\title{
A Visit to an Old Organ
}

Author(s): Sidney W. Harvey

Source: The Musical Times, Vol. 60, No. 921 (Nov. 1, 1919), pp. 618-619

Published by: Musical Times Publications Ltd.

Stable URL: http://www.jstor.org/stable/3701588

Accessed: 22-06-2016 00:21 UTC

Your use of the JSTOR archive indicates your acceptance of the Terms \& Conditions of Use, available at

http://about.jstor.org/terms

JSTOR is a not-for-profit service that helps scholars, researchers, and students discover, use, and build upon a wide range of content in a trusted digital archive. We use information technology and tools to increase productivity and facilitate new forms of scholarship. For more information about JSTOR, please contact support@jstor.org.

Musical Times Publications Ltd. is collaborating with JSTOR to digitize, preserve and extend access to The Musical Times 
by the soloing of the melody. Only the last bar of page 12 needs slight modification. Note that the phrasing of the melody was obviously put in haphazard. It is as bad as some of the passages in Mendelssohn's Sonatas.

Dr. Bennett tells us that Rheinberger gave him the proof sheets of No. Io (B minor) to read at sight. We may well imagine the pupil was too busy to note one or two slips. An E is missing from the alto on the first beat of page 5 . It is the final note of the phrase B A G F, and should be taken with the left-hand. The two pairs of consecutive 5 ths on page 8 sound well, and were probably intentional. The final Allegro is marked $d=63$. This is obviously wrong, though $d=63$ is perhaps a trifle too fast.

In the Pastorale of No. I2 (D flat), Rheinberger directed the melody to be played as a solo, but apparently forgot the fact at the fourth bar. The middle notes should be played on the lower (accompanying) manual, thus:

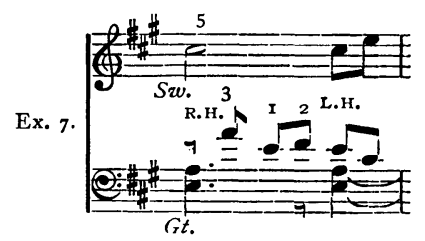

If the hang of the keyboard is not convenient, the first $\mathrm{E}$ in the bass may be played as a quaver, and the whole played with the left-hand. The next few bars present no difficulty, but bars I2-1 5 must be played with the solo part becoming a duet for the time being. As the under part is melodious the effect is quite good, provided there is less disparity in the power of the two manuals than is indicated by the composer's $m f$ and $p$. The two keyboards should be almost equal in power, but of different character.

Similar examples of Rheinberger's forgetfulness will be found in the Canzone of No. 13 (E flat). Here again we must play the passages as written, and minimise the bad effect by our choice of stops. At the end of the Fugue occurs a passage which seems to call for antiphonal effect :

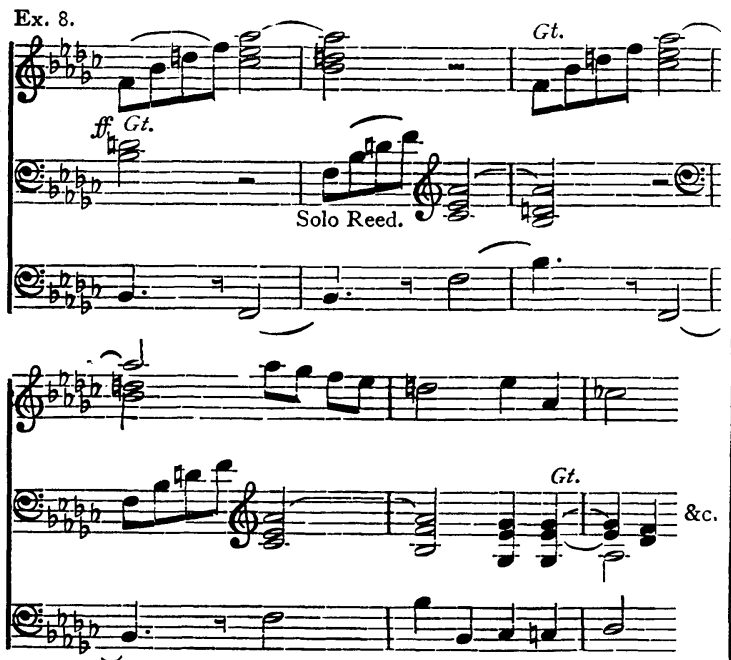

Where a solo reed is available I have found the above a great improvement on the original version for Great organ throughout.

One of the worst examples of the composer's carelessness is on page II of No. I4 (C major), where the theme is marked $p$ and the accompaniment $m f$ :

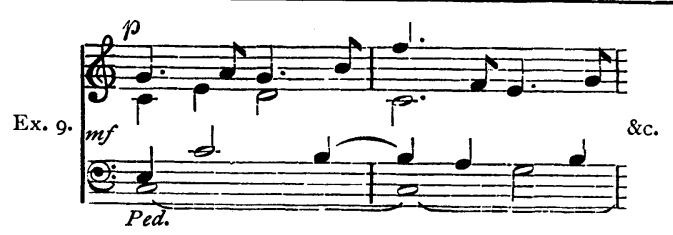

The passage is best played on one manual. Any attempt to solo the treble leads to hopeless difficulties a few bars later.

There are many other points calling for discretion on the part of the player. I have mentioned only some of the less obvious, and one or two over which I have found even experienced performers at sea.

And now for the cream of the Sonatas - the seventeen Fugues and the Passacaglia.

$$
\text { (To be continued.) }
$$

\section{A VISIT TO AN OLD ORGAN.}

By SiDNEy W. HARVEY.

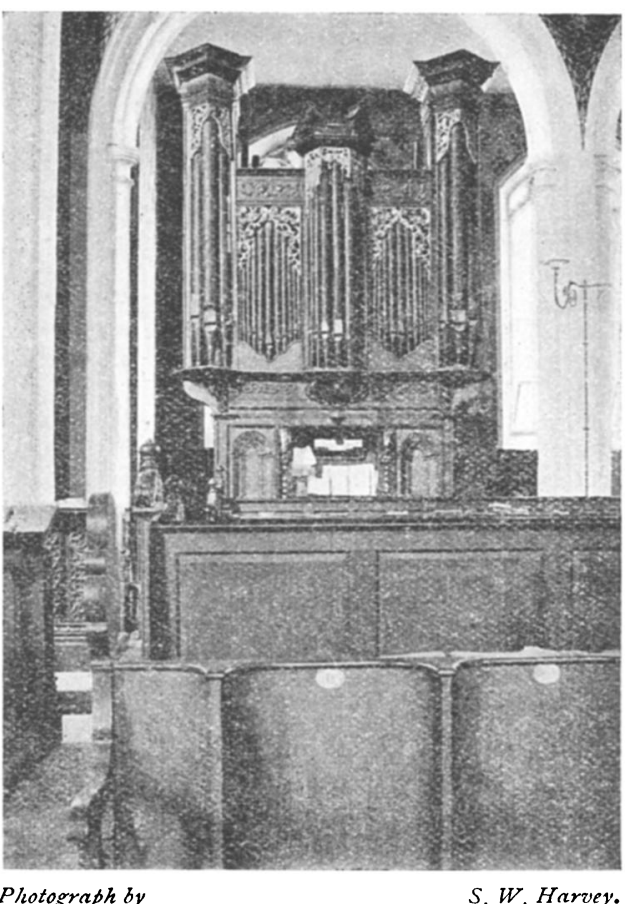

THE FRAMLINGHAM ORGAN.

Passing through Framlingham recently, I seized the opportunity of inspecting the very beautiful church and the historic and charming organ-case. The organ stands under an arch on the north side of the chancel The case varies but little from the careful drawing by the Rev. F. H. Sutton, which forms one of the plates in his 'Church Organs.' The little medallion which is there shown over the centre tower has now disappeared, and I am sorry to say that the beautiful little case which formerly served to screen the organist has been removed from its proper position. It can now be seen nailed on the back of the organ.

By the courtesy of the Vicar, the Rev. H. C. O. Lanchester, I was permitted to take photographs of this gem among organ-cases. It is in a very fair state of preservation, considering its great age, dating back as it does to 1674 , if not to an even earlier year. The pipes which stand in front of the case are now almost black with age, so that it is difficult to distinguish the 
pattern of the handsome diaper with which they are covered. The specification of the organ at the present time is as follows :

\begin{tabular}{lc}
\multicolumn{1}{c}{ Left. } & \multicolumn{1}{c}{ Right. } \\
Oboe, 8-ft. & Bourdon, 8-ft. tone. \\
(Space for knob.) & Tremulant. \\
Principal, 4-ft. & Gamba, 8-ft. \\
Iieblich Gedact, 8-ft tone. & Flute Harmonique, 4-ft. \\
Open Diapason, 8-ft. & Fifteenth, 2-ft. \\
Dulciana, 8-ft. & (Knob without label.) \\
Swell to Great. & Principal, 4-ft. \\
(Space for knob.) & Open Diapason, 8-ft. \\
Great to Pedal. & Stop Diapason, 8-ft. tone. \\
The compass of the Manuals is from CC to F, and of the pedals \\
from CCC to E. There are no composition pedals.
\end{tabular}

The organ was built in 1674 for Pembroke College, Cambridge, by Thamar, of Peterborough, who, it will be remembered, was one of the four 'tolerable organ builders' remaining in this country at the Restoration. The organ then consisted of one manual with white sharps and black naturals and the following eight stops :

$\begin{array}{ll}\text { Open Diapason. } & \text { Fifteenth. } \\ \text { Stop Diapason (oak). } & \text { Sesquialtera. } \\ \text { Principal. } & \text { Cornet. } \\ \text { Twelfth. } & \text { Trumpet. }\end{array}$

Compass GG to D.

At a later period a Swell of four stops was added, the compass of which was from Tenor $F$ to $D$, viz. :

$$
\begin{array}{ll}
\text { Stop Diapason. } & \text { Open Diapason. } \\
\text { Principal } & \text { Oboe. }
\end{array}
$$

According to the Rev. F. H. Sutton, the organ was originally placed in the chancel, but was apparently removed to the West Gallery, where it was situated at the time that Mr. Sutton saw it. Later it was returned to the chancel, for in the Musical Standard of November 30, I889, we read that the organ was dismantled to allow of the necessary alterations to the chancel. It was intended then to be restored and replaced, and at the same time to be enlarged, so as to consist of some 40 stops, together with three manuals and pedal. The organ was certainly replaced in the position it occupies to-day, but only a slight enlargement was carried out, a Dulciana 8 -ft. being added to the $S$ well and the Stop Diapason renamed Lieblich Gedact, 8-ft. tone, while on the Great organ the Sesquialtera, Cornet, and Trumpet were taken out and a Flute Harmonique 4 - $\mathrm{ft}$. and Gamba 8-ft. inserted in their place. Other additions at this time were the Tremulant, the pedal board, the two couplers Swell to Great and Great to Pedal, and the Bourdon 8-ft. tone.

The stop knob which has lost its label is apparently the Twelfth.

The little case, which was formerly used to screen the organist, is evidently part of a former organ in this church. This, together with its dummy pipes, is entirely of wood and is in a fine state of preservation. It is to be regretted that it does not continue to occupy the position it once held, where besides being of use as a screen it was also an object of beauty and added considerable charm to the organ itself.

A very excellent account of this pre-Reformation case is contained in the valuable article on 'English Organ Cases,' by the Rev. Andrew Freeman, which was published in the 'Dictionary of Organs and Organists,' 1912, and which merits careful study.

Mr. Freeman thinks that the case is considerably older than 1674-probably circa I550. 'Here again,' he says, "there is some reason to believe that an old case was used up to contain Thamar's new instrument, for its style led both Mr. Sutton and Mr. Hill to ascribe it to the reign of Henry VIII., though it is only fair to add that Mr. Hill withdrew from this position upon learning the dates given above.'

\section{The SDusician's JBooksbelf.}

\author{
By 'FESTE.'
}

One of the best auguries for the future of music is the increasing amount of space given to the subject in the non-musical Press. The leading London and provincial dailies, and many of the weekly and monthly journals, contain regular musical articles by writers of repute. A huge public, outside the influence of the musical periodicals, is thus kept in more or less regular touch with the art. The best of these musical writers are far more attractive than were the old-time critics. They are less pompous in diction, and their work is clearly the product of brains well-stored with a good deal beside music. It often shows real literary distinction, and many of us must have regretted when some specially good article had to be cast aside with the newspaper in which it appeared or be kept in the inconvenient form of a cutting. I can think off-hand of half-a-dozen musical scribes whose file of past articles deserves to be overhauled with a view to republication in book form. Here is one of them, Mr. Ernest Newman, showing the way with a collection containing about fifty papers under the title of 'A Musical Motley' (John Lane). It goes without saying that the essays cover a wide field, and that the book is thoroughly entertaining and stimulating. A few of the articles were hardly worth rescuing, we shall all venture to think, but as we shall mostly disagree as to which ones are below par, Mr. Newman's choice is sufficiently vindicated. A book of this kind is like an anthology: the readers are never unanimous about more than two-thirds of the selection. I fancy, however, that there will be a general feeling that the paper on 'Composers and Obituary Notices' is an uncomfortable piece of jesting that never would be missed. Here are a few sentences that might pass well enough as banter in conversation (aided by facial play and tone of voice, and a free-andeasy atmosphere), but which come off much less well in print-and especially in reprint :

In common with other journalists, I have a grievance against the ordinary musician. Death comes to all men sooner or later; but no man of eminence who is living quietly and safely at home, and can more or less choose the time of his own dying, has a right to depart this life without remembering his obligations of honour to his biographers. I speak feelingly on this subject, for some of these gentlemen have put me to a good deal of inconvenience by their irregular and inconsiderate way of dying. Many of those who still survive are very decent fellows, and I feel I have only to make my grievance known to them to recognise the necessity for a little kindly forethought on their part.

And, speaking of the obituary notices of public men, which are written and kept up-to-date ready for use :

I warn my friends that I have said some horrible things about them in their obituaries, things that would make them dislike me for the rest of their days if I were to publish them now. I see no reason to show these people any consideration when they show me so little. A decent man would recognize that an obituary notice costs the conscientious writer of it a good deal of time and trouble, and he would recognize that the least he can do is to see that all this labour of love is not in vain. Instead of which, most of these people persist in living an unconscionable time after their obituaries have been done, with the result that the critic has to keep adding to them, and in some cases revising his point of view. - . But in even worse taste than living on after your obituary is written, is dying before it is written. I myself had left Scriabin and Max Reger over because I thought there was no hurry in the case 